\title{
The role of mentoring in public health nutrition workforce development. Perspectives of advanced-level practitioners
}

\author{
Claire Palermo ${ }^{1, *}$ and Louise McCall ${ }^{2}$ \\ ${ }^{1}$ Monash University, Nutrition and Dietetics, Faculty of Medicine, Nursing and Health Sciences, Level 5 Block E \\ Monash Medical Centre, 246 Clayton Road, Clayton, Victoria 3168, Australia: ${ }^{2}$ Monash University, Faculty of \\ Medicine, Nursing and Health Sciences, School of Primary Health Care, Normanby House, Clayton Campus, \\ Clayton, Victoria 3800, Australia
}

Submitted 16 April 2007: Accepted 6 March 2008: First published online 22 April 2008

\begin{abstract}
Objective: To explore the nature, role and utility of mentoring in the development of competence in advanced-level Australian public health nutritionists.

Design: Qualitative study using in-depth interviews.

Subjects and setting: Eighteen advanced-level public health nutritionists working in academic and practice settings in Australia.

Results: The attributes and career pathways of the subjects were consistent with previous findings. Dissatisfaction with clinical practice was a key reason for choosing a career in public health. Experiential learning, postgraduate education and mentoring from both peers and senior colleagues were the most significant contributors to competency development. The subjects supported mentoring as an important strategy for public health nutrition workforce development and articulated the characteristics and models important for mentoring relationships in public health nutrition.

Conclusions: The present study suggests mentoring was an important part of competency development for advanced-level public health and community nutritionists in Australia. Mentoring programmes based on experiential learning may assist in developing public health nutrition workforce competence.
\end{abstract}

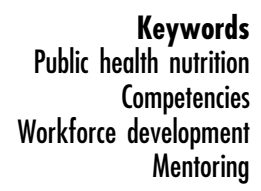

The public health workforce is an important determinant of a population's capacity to address public health issues. This workforce internationally faces great challenges in being able to address current and future population health issues ${ }^{(1)}$. Efforts to enhance public health workforce capacity must consider a range of strategies, including enhancing workforce practices and competence and developing organisational capacity $^{(2)}$. All have been recognised as vital elements for action to address public health workforce development ${ }^{(3)}$.

There is evidence to suggest that the Australian public health nutrition workforce lacks the capacity to respond to the national population health needs ${ }^{(4-6)}$. This workforce is small in size and has reported a wide range of competency development needs ${ }^{(7)}$. Competency development is a key element of workforce development and refers to the attainment of a set of knowledge, skills and attitudes that enable effective performance in the workplace $^{(8)}$. Competency standards or competencies are statements about a work role that are used to assist with credentialing, which in turn is a system that ensures individuals' competence to practice ${ }^{(8)}$. There has been work undertaken to articulate public health and public health nutrition competency standards or competencies $^{(3,8,9)}$.

The temporal sequence of competency development is important to consider in the context of the workforce. It is recognised that many public health nutrition competencies are developed after entry into the workforce ${ }^{(8)}$. As a consequence, a focus on workforce preparation as a basis for workforce development is likely to have limited impact. Postgraduate professional development therefore is an important workforce development strategy ${ }^{(1,5,7)}$. While postgraduate tertiary education programmes have been acknowledged as a way forward, other approaches need to be explored ${ }^{(10)}$.

Public health nutrition competence has been reported to be most effectively developed through experiential learning ${ }^{(11)}$. Experiential learning is the process of learning through actual and practical experience in the workplace. A variety of experiential learning models are utilised to develop health workforce competence, including apprenticeships, mentoring and clinical supervision $^{(12)}$. Experiential learning without effective supervisory and support infrastructure can lead to ineffective and unsafe practice ${ }^{(12)}$. 
Mentoring is defined as a reciprocal, mutual and supportive learning relationship ${ }^{(13)}$. It is an example of an experiential learning model which has been used to bridge the theory-practice gap successfully within health, education, business and other settings ${ }^{(13)}$. Mentoring has been demonstrated as an effective method for developing public health competency ${ }^{(14-23)}$ and proposed as a framework for developing public health nutrition workforce capacity in Australia ${ }^{(8)}$. Public health nutritionists in Australia have previously recognised the role of mentoring as contributing to competency development ${ }^{(7,24)}$. There is evidence to suggest that mentoring in the public health field creates opportunities for networking and access to resources, improves career and personal satisfaction, increases professional and interpersonal skills, increases confidence, and develops reflection for both the mentee and mentor ${ }^{(14-23)}$. Despite this, specific models and practical examples of mentoring to enhance workforce development in public health nutrition have not been published.

The present study explores the role and nature of mentoring in the development of public health nutrition competence as experienced by advanced-level public health nutritionists in Australia during their professional development. The investigation aimed to identify and describe features of the mentoring process as a strategy for workforce development in public health nutrition.

\section{Methodology}

\section{Design}

A qualitative study using in-depth interviews was carried out among a purposive sample of eighteen Australian public health nutrition exemplars. Ethics approval was obtained from Monash University human ethics committee.

\section{Recruitment}

Advanced-level public health nutritionists, previously defined in earlier studies as 'senior government-level public health nutrition practitioners and academic public health nutritionists from Australian Universities with programmes in professional nutrition practice ${ }^{(7)}$, were recruited from a web-based search of Australian state government health departments and universities with programmes in public health and community nutrition. Purposive sampling was used to cater for a range of different work positions and experiences within academic and practical settings ${ }^{(25)}$. Potential subjects were contacted by email and telephone and invited to participate in the study.

\section{Data collection}

Interview data were collected between August and November 2006. Face-to-face interviews were conducted when possible and telephone interviews were conducted, for convenience and owing to resource limitations, for subjects generally in other states. A set of open-ended
Table 1 Interview schedule: advanced-level Australian public health nutritionists, August-November 2006

What has been your career path to get to your current role?

What were the events or experiences that contributed most to your own competency development?

Can you identify any mentor or role model relationships that have impacted on your career development? Can you describe these experiences?

Based on your experience what are the attributes of a good mentor? What are the attributes of a good mentor-mentee relationship?

How effective do you think a mentoring programme specific to public health and community nutrition would be in increasing competencies? Why do you think this?

What are the important attributes, structures, elements that need to be considered for the design of a mentoring programme?

Have you played a role as a mentor? Can you describe your role and the relationship? What did you enjoy about this role? What were the barriers you encountered?

What characteristics in a dietitian would be required as a mentor in public health and community nutrition?

questions, adapted from an earlier investigation of advanced-level practitioners' workforce development issues (see Table 1) ${ }^{(24)}$, was provided to each subject prior to the interview to allow subjects to reflect and give considered responses. Interviews lasted approximately an hour. Data were collected until the researchers were satisfied that that data were rich enough and covered adequate dimensions of the topic being investigated. Interviews were transcribed in full and sent to the subjects to allow the opportunity to clarify and verify discussions recorded. Fifteen transcripts were edited by the subjects for grammatical errors to improve readability.

\section{Analysis}

Interview transcripts were analysed manually by the first author using a content analysis approach ${ }^{(25)}$. Four interview transcripts (one face-to-face, three telephone) were chosen for separate analysis by the second author with a background in health, education and adult learning to verify analytical consistency. Of these, one was from a male and the remainder from female subjects from practice and academic backgrounds. Responses from transcripts were grouped by themes into categories. The analysis included assessment of difference in the degree of data obtained from face-to-face $v$. telephone interviews. Key themes were then summarised and interpreted by the authors, and narrative scripts selected to represent the range of subjects and provide the best illustration of the findings and themes.

\section{Results and discussion}

\section{Attributes and career pathways of advanced-level public bealth nutritionists}

Eighteen advanced-level public health nutritionists were interviewed. Data were collected by face-to-face ( $n$ 4) 
Table 2 Participant demographics: advanced-level Australian public health nutritionists, August-November 2006

\begin{tabular}{|c|c|c|c|c|c|c|}
\hline & \multicolumn{2}{|c|}{ Academic $(n 6)$} & \multicolumn{2}{|c|}{ Practitioner ( $n$ 12) } & \multicolumn{2}{|c|}{ Total $(n 18)$} \\
\hline & Mean & SD & Mean & SD & Mean & SD \\
\hline \multicolumn{7}{|l|}{ Gender } \\
\hline Male & \multirow{2}{*}{\multicolumn{2}{|c|}{$\begin{array}{l}3 \\
4\end{array}$}} & \multirow{2}{*}{\multicolumn{2}{|c|}{$\begin{array}{r}0 \\
11\end{array}$}} & \multicolumn{2}{|c|}{3} \\
\hline Female & & & & & \multicolumn{2}{|c|}{15} \\
\hline Number of tertiary qualifications & 4.2 & 0.8 & 3.3 & 1.1 & 4 & 1 \\
\hline Years of experience in community and public health nutrition practice & 24.6 & 10.4 & 19.5 & 6.5 & 21 & 8 \\
\hline Number with doctorate-level qualifications & \multicolumn{2}{|c|}{5} & \multicolumn{2}{|c|}{1} & \multicolumn{2}{|c|}{6} \\
\hline Number with Master of Public Health & \multicolumn{2}{|c|}{2} & \multicolumn{2}{|c|}{6} & \multicolumn{2}{|c|}{7} \\
\hline Number of members of the Dietitians Association of Australia & \multicolumn{2}{|c|}{5} & \multicolumn{2}{|c|}{10} & \multicolumn{2}{|c|}{15} \\
\hline
\end{tabular}

and telephone ( $n$ 14) interviews. Both face-to-face and telephone interview techniques were determined by both authors to obtain the same degree of data, as has been found elsewhere ${ }^{(26)}$. All states of Australia were represented by the subjects (five in Victoria, four in New South Wales, two in Northern Territory, two in Tasmania, two in Queensland, one in South Australia, one in Western Australia and one in Australian Capital Territory). Demographic data of study subjects (see Table 2) were similar to those interviewed previously ${ }^{(7,24)}$.

In response to being asked about their career path towards their current role, most of the subjects reported that their careers commenced in clinical practice and then moved into public health nutrition. This has been reported previously as most likely a reflection of the health-care system and professional issues in Australia ${ }^{(7,24)}$. The lack of career structure in clinical practice and the frustration with the inability to make long-term, significant changes to people's health were cited as contributing to a career choice in public health. This is consistent with other work that described the dissatisfaction with clinical dietetics and a need to be effectual as drivers to a career in public health nutrition $^{(24)}$.

The data suggest that the current advanced-level public health nutritionists in Australia are among the first group of nutritionists to be part of a formal workforce system in Australia. They have been pioneers, breaking new ground in moving away from the traditional clinical dietitian role into public health and community nutrition. Being the first designated workforce limited their opportunities for professional development and mentoring relationships from more senior professionals in the field:

Initially there weren't any real role models - there wasn't anyone. (Nutritionist 15)

\section{Influences on public bealtb nutrition competency development}

The data indicate that experience, training and learning informally from others (both peers and more senior colleagues) have been the influential events and experiences that contributed most to the advanced-level nutritionists' competence. Learning on the job was instrumental in shaping competency. Although training or postgraduate qualifications were deemed important, not all of the subjects had access to these types of programmes. Being constantly challenged by work roles developed the nutritionists to advanced level. They sought challenging career roles and moved early into advanced-level responsibility. Public health working environments, such as those seen when working in Indigenous health, provided rapid orientation to the importance of working to address the broader determinants of health:

...being allowed to develop my style and then being thrown in the deep end in a sole community nutrition role. (Nutritionist 5)

I could never have come into my current role before seeing how hard healthy choices can be for some people... Seeing health inequalities and great despair made me realise the difference I needed to make... You have to see disadvantage, you can't read it. (Senior nutritionist 2)

The results support the role of experiential or 'on-thejob' learning as a significant contributor to competency development in public health ${ }^{(11,24)}$. The learning undertaken by the subjects involved reflective practice and recognised the role that both personal and social experiences have in shaping learning. These characteristics of learning are described by experiential learning theory $^{(12)}$. This theory argues that it is not experiential learning on its own that contributes to the attainment of new skills, but a range of other opportunities that are available in the experiential learning environment ${ }^{(12)}$ :

I was the first nutritionist... and I was required to start things up from scratch... where I learnt a lot about my own capacity to start new initiatives in unknown territory in an environment that was completely different to my own. (Nutritionist 1)

Half of the advanced-level nutritionists, representing both practice and academic settings, reported mentoringlike relationships as contributing to their competency development. Although often working alone, most could 
still identify positive mentoring-like relationships, focused on trust, support and learning, during their career development:

I had some strong mentors... They were instrumental for me in developing my competency. (Nutritionist 5)

Hearing them [mentors] talk about their work was inspiring. I learnt a lot from them talking about their experiences. (Nutritionist 11)

All of the subjects could identify a mentor or role model relationship that impacted on their career development when specifically asked to reflect on this. The subjects indicated that mentoring had a positive impact on professional and personal development in public health and community nutrition and that these workplace environments support ongoing mentoring-type relationships. The significance of mentoring in the development of the public health nutritionists' careers was illustrated in the fact that many felt an obligation to be involved in mentoring:

I feel a responsibility now to provide that back to people what I was so lucky to have given to me. (Nutritionist 7)

These data support previous findings that mentors, workplace experiences and postgraduate education were the significant experiences that contributed most to competency development ${ }^{(24)}$. The recognition of the value of mentoring in developing competency by this group, who are responsible for shaping the upcoming workforce, provides a pathway to foster mentoring within public health nutrition.

\section{The role of mentoring}

When asked whether a mentoring programme specific to public health and community nutrition would increase competency, there was general agreement that mentoring provides leadership and advice in the knowledge, skills and attitudes required to perform public health. It also provides a sounding board for managing politics and the frustrations in waiting to see long-term outcomes in public health. The subjects indicated that the isolating nature of public health work would be supported well with mentoring:

It is important. It [a mentoring programme for public health nutrition] humanizes much of the learning and if done well helps people to learn from other people. (Nutritionist 6)

However, they acknowledged that a mentoring programme specific to public health and community nutrition is only part of the solution to the workforce issues in Australia. They argued that workforce development requires further education in public health as well as increased workforce capacity and clear career paths. Some felt that there were already adequate mentoringlike arrangements in place in Australia:

Mentoring is not the only solution, there needs to be a package, but mentoring is a significant part of this package... You need personal interaction to guide you in understanding the political context of public health nutrition - you can't learn this from a textbook! (Nutritionist 5)

Workforce development in public health nutrition has been proposed to include strategic investment in human resource infrastructure, a supportive organisational and policy environment, and access to and use of evidencebased public health nutrition interventions ${ }^{(2,6)}$. The present investigation further supports an integrated, multidimensional approach to public health nutrition workforce development.

\section{Characteristics of the mentoring relationship}

Reflecting on their experiences of mentoring both as a mentor and mentee, the important characteristics of mentoring identified by the advanced-level nutritionists were the reciprocal, trusting and inspiring nature of the relationship. They claimed that mentors need to be experienced and have the appropriate skills to teach others:

[Mentors] inspire you in a way that is life-changing or career-changing or significantly changes the way you are forever going to be. Mentoring is profound. They look at a situation and work with it to a whole new way of being. (Nutritionist 2)

Someone who is very good at what they do, very knowledgeable and very willing to share. They need to be tolerant and have patience for people who know less and be good time managers to make space for people so they feel like they are not impinging. (Nutritionist 8)

The nutritionists reported that mentoring relationships contributed to their problem-solving skills. Mentors were viewed as coaches that guided, rather than told, and enlightened awareness of future career prospects. The importance of measuring outcomes of the mentoring relationship was acknowledged:

They [mentors] make you find the solution rather than giving it to you. This is how they approach their own work... [Mentors need to be] problem solvers and not necessarily have clear answers but part of the relationship is about working together to find the best way forward. (Nutritionist 13)

When you are mentoring someone it is warm and fuzzy. You need to practice getting outcomes and product to develop competence. (Nutritionist 12) 
The subjects also acknowledged the challenging nature of the relationship including time barriers, geographical distance, low level of commitment from mentees, poor mentor skills and a lack of clearly articulated outcomes for the relationship. These attributes of mentors and the mentoring relationship described by the advanced-level nutritionists were consistent with the literature ${ }^{(13)}$. Further research is needed to determine if mentoring is more effective in developing specific competencies.

When asked about mentoring relationships and their impact on the advanced-level nutritionists' career development, a range of mentoring models including informal and formal, one-to-one, group and peer mentoring were experienced. Much of the mentoring relationships described were informal and grew from existing relationships with supervisors and colleagues. Individuals from other professional groups were used as mentors in public health nutrition, which is not surprising given the multidisciplinary and multisectoral nature of public health nutrition practice ${ }^{(8)}$ :

I haven't had one person as my mentor but more developing a team of people with different skills that contributed and helped build my competence... we talked about what we are going to do and how we will do it. Formally we would sit around a table where all issues were discussed and that spilled over into informal mentoring where you would go to people for their help. (Nutritionist 9)

Informal mentoring relationships are acknowledged in the literature as contributing to professional development and offering greater potential for outcomes ${ }^{(27)}$; however, there is an emphasis on recommending structured and formalised mentoring programmes ${ }^{(13)}$. The present study identified the important role of informal mentoring relationships in public health nutrition. There is risk in assuming that the characteristics described by the subjects as important for mentoring in public health nutrition can be easily replicated in a formal mentoring programme. The nurturing environments and sharing culture described by the subjects may be unique to public health practice. There is evidence to suggest that this willingness to support peers and junior colleagues is not present in treatment-focused health settings ${ }^{(28)}$.

The range of experiences of mentoring aligns with the multiple mentor experience model ${ }^{(29)}$. This model recognises that mentees access several experienced, supportive persons from which to seek guidance and advice, and recognises the function of role models, coaches and supervisors as well as mentors in contributing to the mentees' development ${ }^{(29)}$. This model recommends that organisations, peers and academics have a role in mentoring the public health nutrition workforce ${ }^{(29)}$. This multiple mentor model that increases competency in public health nutrition must centre on reciprocity, trust and inspiration in the development of new skills and in career planning. These characteristics are unique to mentoring and support the descriptions and outcomes of mentoring from the wider health professional literature ${ }^{(13)}$. Other relationships, such as supervision, which includes assessment or performance management, are recognised in developing skills ${ }^{(12)}$. However, assessment of performance that is inherent in a supervisory relationship impacts on trust and the development of attitudes and career aspirations important for public health workforce development.

There is a wealth of knowledge on the structure and function of mentoring relationships available to be drawn upon when planning mentoring programmes for public health nutrition. Formality, training of mentors and organisational support are significant factors identified as important for success in mentoring relationships ${ }^{(13)}$. The present study suggests that while formalised, clearly articulated outcomes for the mentoring partnership are important, informal mentoring relationships can develop competence. Subjects explained that organisational support is important to allow adequate time and resources for mentoring. Given the fundamentally political nature of public health nutrition practice, the conflict between personal and professional development and organisational development must be recognised:

There is a risk in formalising it that you create a bureaucracy around something that was working well so that it is not effective. (Nutritionist 13)

Organisational support is only required when work time is required to develop the mentoring relationship. Public health and community nutrition may require personal and professional development in your own time. Organisational support may not be there because they are not on the same political side. (Nutritionist 5)

Informal mentoring relationships appear to be a unique and important aspect for workforce development in public health nutrition.

\section{Conclusion}

Public health nutrition competence is recognised as an important component of workforce development. The present study provides the evidence to support the development of mentoring as a tool to promote competency in public health nutrition. Mentoring must be considered as part of a multistrategy approach to competency development in public health nutrition and needs to be incorporated into future policy and planning for workforce development.

\section{Acknowledgements}

The constructive feedback of the anonymous reviewers and the participation of the eighteen advanced-level practitioners in this study are acknowledged. 
Sources of funding: The study was conducted as part of C.P.'s PhD research project supported by Monash University Department of Nutrition and Dietetics.

Conflict of interest declaration: The authors declare that they have no competing interest.

Authorship responsibilities: C.P. with the assistance of A/Prof Roger Hughes was responsible for the initial conception and design of the study. Both C.P. and L.M. analysed and interpreted the data. C.P. drafted the initial and final manuscripts and L.M. provided detailed critical review.

\section{References}

1. Gebbie K, Merrill J \& Tilson HH (2002) The public health workforce. Health Aff (Millwood) 21, 57-67.

2. Hughes R (2003) A conceptual framework for intelligencebased public health nutrition workforce development. Public Health Nutr 6, 599-605.

3. Lichtveld MY \& Cioffi JP (2003) Public health workforce development: progress, challenges, and opportunities. $J$ Public Health Manag Pract 9, 443-450.

4. Hughes R (2004) Enumerating and profiling the designated public health nutrition workforce in Australia. Nutr Diet 61, 162-171.

5. Hughes R (2004) Work practices of the community and public health nutrition workforce in Australia. Nutr Diet 61, 38-45.

6. Hughes R (2006) A socioecological analysis of the determinants of national public health nutrition workforce capacity. Fam Community Health 29, 55-67.

7. Hughes R (2003) Public health nutrition workforce composition, core functions, competencies and capacities: perspectives of advanced-level practitioners in Australia. Public Health Nutr 6, 607-613.

8. Australian Public Health Nutrition Academic Collaboration (2004) Home page on the Internet. http://www.aphnac. com/workforce.php (accessed February 2008).

9. Hughes R (2003) Competencies for effective public health nutrition practice: a developing consensus. Public Health Nutr 7, 683-691.

10. Meddings D (2007) Mentor-VIP - a global mentoring program for violence and injury prevention. Inj Prev $13,69$.

11. Pelletier D (1997) Advanced training in food and nutrition: disciplinary, interdisciplinary and problem oriented approaches. Food Nutr Bull 18, 120-133.

12. Kaufman DM, Mann KV \& Jennett PA (2000) Teaching and Learning in Medical Education: How Theory Can Inform Practice. Edinburgh: Association for the Study of Medical Education.
13. Walker WO, Kelly PC \& Hume RF (2002) Mentoring for the new millennium. Med Educ Online 7, issue 15; available at http://www.med-ed-online.org/

14. Langerich EJ, Siedlecki JC, Brownson R, Aldrich TE, Hedberg K, Remington R \& Siegel PZ (2003) Mentorship and competencies for applied chronic disease epidemiology. J Public Health Manag Pract 9, 275-283.

15. Howe A, Billingham K \& Walters C (2002) Helping tomorrow's doctors to gain a population health perspective - good news for community stakeholders. Med Educ 36, 325-333.

16. Quinn G, Albrecht T, Marshall R Jr \& Akintobi TH (2005) 'Thinking like a marketer': training for a shift in the mindset of the public health workforce. Health Promot Pract $\mathbf{6}$, $157-163$

17. Mahayosnand PP \& Stigler MH (1999) The need for mentoring in public health. Am J Public Health 89, 1262-1263.

18. Leatherdale ST, Viehbeck S, Murphy C, Norman C \& Schultz ASH (2007) The tobacco control community of tomorrow. A vision for training. Can J Public Health 98, 30-32.

19. Love RR \& Engstrom PF (1996) Cancer prevention and control investigators: the need for high quality training programs. Cancer Epidemiol Biomarkers Prev 5, 141-142.

20. Doutrich D \& Storey M (2004) Dynamic partners for improving cultural competence in public health. Fam Community Health 27, 298-307.

21. Zahner SJ (2006) Partnerships for learning populationbased public health nursing: web-delivered continuing education for public health nurse preceptors. Public Health Nurs 23, 547-554.

22. Ronczkowski PJ, LaFollette S \& Bellingar T (2004) The role of an environmental health professional-practice (internship) coordinator in mentoring the student intern. J Environ Health 66, 22-26.

23. Green BL, Rivers BM \& Arekere DM (2006) Mentoring: a framework for developing health disparities researchers. Health Promot Pract 7, 336-345.

24. Hughes R (2003) Competency development in public health nutrition: reflection of advanced level practitioners in Australia. Nutr Diet 60, 205-211.

25. Liamputtong P \& Ezzy D (2005) Qualitative Research Methods, 2nd ed. Oxford: Oxford University Press.

26. Sturges JE \& Hanrahan KJ (2004) Comparing telephone and face-to-face qualitative interviewing: a research note. Qual Res 4, 107-118.

27. Bally JM (2007) The role of nursing leadership in creating a mentoring culture in acute care environments. Nurs Econ 25, 143-148.

28. Ragins BR \& Cotton JL (1999) Mentor functions and outcomes: a comparison of men and women in formal and informal mentoring relationships. J Appl Psychol 84, $529-550$

29. Nolinske $T$ (1995) Multiple mentoring relationships facilitate learning during fieldwork. Am J Occup Ther $\mathbf{4 9}$, $39-43$. 